\title{
Long-term quality of life improvement for chronic intractable back and leg pain patients using spinal cord stimulation: 12-month results from the SENZA-RCT
}

\author{
Kasra Amirdelfan ${ }^{1}$. Cong Yu ${ }^{2} \cdot$ Matthew W. Doust $^{3} \cdot$ Bradford E. Gliner $^{4} \cdot$ Donna M. Morgan $^{5} \cdot$ Leonardo Kapural $^{6}$. \\ Ricardo Vallejo ${ }^{7} \cdot$ B. Todd Sitzman ${ }^{8} \cdot$ Thomas L. Yearwood $^{9} \cdot$ Richard Bundschu $^{10} \cdot$ Thomas Yang $^{2}$. \\ Ramsin Benyamin ${ }^{7}$. Abram H. Burgher ${ }^{3}$. Elizabeth S. Brooks ${ }^{4}$. Ashley A. Powell ${ }^{4}$ Jeyakumar Subbaroyan ${ }^{4}$
}

Accepted: 22 May 2018 / Published online: 1 June 2018

(c) The Author(s) 2018

\begin{abstract}
Purpose Chronic axial low-back pain is a debilitating disorder that impacts all aspects of an afflicted individual's life. Effective, durable treatments have historically been elusive. Interventional therapies, such as spinal cord stimulation (SCS), have shown limited efficacy at best. Recently, a novel treatment, $10 \mathrm{kHz} \mathrm{SCS}$, has demonstrated superior pain relief compared with traditional SCS in a randomized controlled trial (RCT). In this manuscript, we report on the long-term improvements in quality of life (QoL) outcomes for subjects enrolled in this study.

Methods A prospective, multicenter, randomized controlled trial (SENZA-RCT) was conducted. Patients with both chronic back and leg pain were enrolled and randomized (1:1) into $10 \mathrm{kHz}$ SCS or traditional SCS treatment groups. A total of 171 subjects received a permanent SCS device implant. QoL and functionality measures were collected up to 12 months. The device remote control utilization, which is an indication of patient interaction with the device for adjustments, was collected at 24-month post-implantation.

Results At 12 months, a higher proportion of $10 \mathrm{kHz}$ SCS subjects had marked improvement of their disability (Oswestry Disability Index) to a "moderate" or "minimal" impact on their daily function versus the control group. The subjects also reported better improvement in the Global Assessment of Functioning, Clinician Global Impression of Change, Pittsburgh Sleep Quality Index, and short-form McGill Pain Questionnaire, compared to traditional SCS subjects. The $10 \mathrm{kHz}$ SCS subjects also reported far higher rates of both driving and sleeping with their device turned on, as well as reduced reliance on their programmers to adjust therapy settings.

Conclusions In addition to superior pain relief, $10 \mathrm{kHz}$ SCS provides long-term improvements in quality of life and functionality for subjects with chronic low-back and leg pain. Trial registration: ClinicalTrials.gov (NCT01609972).
\end{abstract}

Keywords Spinal cord stimulation · Quality of life $\cdot$ Neuropathic pain $\cdot 10 \mathrm{kHz} \cdot$ High-frequency SCS $\cdot$ Chronic low-back pain $\cdot$ Leg pain

Jeyakumar Subbaroyan

jey.subbaroyan@nevro.com

IPM Medical Group, Inc., Walnut Creek, CA, USA

2 Swedish Pain Center, Seattle, WA, USA

3 The Pain Center of Arizona and HOPE Research Institute, Phoenix, AZ, USA

4 Clinical Affairs, Nevro Corp., 1800 Bridge Parkway, Redwood City, CA 94065, USA

5 Pain Specialists of Oregon, Eugene, OR, USA
6 Center for Clinical Research and Carolina's Pain Institute at Brookstown, Wake Forest Baptist Health, Winston-Salem, NC, USA

7 Millennium Pain Center, Bloomington, IL, USA

8 Advanced Pain Therapy, PLLC, Hattiesburg, MS, USA

9 Comprehensive Pain and Rehabilitation, Pascagoula, MS, USA

10 Coastal Orthopedics and Pain Medicine, Bradenton, FL, USA 


\section{Introduction}

For the past two decades, low-back pain has been the single leading cause of disability worldwide, affecting 9.2\% of the population $[1,2]$. Chronic, intractable back pain dramatically affects one's work function, activities of daily living, as well as social relationships with friends and family members. In addition, the global pervasiveness and intractable nature of this ailment, as the leading cause of disability in the population, results in tremendous healthcare utilization [3-5] and loss of workforce productivity $[6,7]$. Treatments for chronic pain currently include exercise, physical therapy, psychological support, pharmaceuticals, interventional procedures, neuromodulation, and surgery. However, the evidence of efficacy of such treatments is limited for many chronic pain patients [8]. Thus, there is great need for improved treatment options for patients living with chronic low-back and leg pain, in order to not only reduce their pain, but to also improve their quality of life (QoL).

Spinal cord stimulation (SCS) is a well-established treatment option for chronic neuropathic pain arising from various etiologies [9-12]. Traditional SCS utilizes an array of electrodes placed in the epidural space to deliver low-frequency $(\sim 50 \mathrm{~Hz})$ electrical stimulation to the dorsal column nerve fibers. This therapy depends on the induction of paresthesias (tingling or buzzing sensations) overlapping the patient's pain distribution [13]. Paresthesias are caused by the activation of large diameter $\mathrm{A} \beta$ fibers [14]. While it has been found to be an effective treatment for chronic, intractable neuropathic pain [15, 16], published evidence demonstrates that pain relief from traditional SCS may not be sustained over the long-term. Moreover, traditional SCS may not effectively treat axial low-back pain [15, 17-19]. The arrangement of dorsal column fibers innervating the axial back makes it difficult to elicit paresthesias in this region using traditional SCS. Moreover, the intensity of these paresthesias can also vary, based on body position resulting in either a sudden, uncomfortable increase in stimulation or persistent unwanted sensations [20,21]. This precludes the use of traditional SCS during sleeping, driving, and operating machinery. Thus, there remains great potential for improved efficacy of neuromodulation as an attractive alternative to both conventional medical management and more invasive surgical procedures.

Recently, a neuromodulation therapy utilizing a highfrequency, $10 \mathrm{kHz}$ stimulation waveform (HF10 therapy) has emerged as a promising therapeutic option. This therapy involves percutaneous leads placed in the epidural space, similar to traditional SCS. But a combination of anatomical midline lead placement and stimulation parameters results in paresthesia-free pain relief with $10 \mathrm{kHz}$ SCS. In a multicenter, randomized controlled trial (SENZA-RCT), $10 \mathrm{kHz}$ SCS demonstrated superior, long-lasting back and leg pain relief, when compared to traditional, low-frequency SCS without the need for painparesthesia overlap [22, 23]. At 12 months, the responder rates ( $\geq 50 \%$ pain relief) for the $10 \mathrm{kHz}$ SCS and lowfrequency SCS were $76.5 \%$ and $49.3 \%$ for back pain and $72.9 \%$ and $49.3 \%$ for leg pain, respectively. Pain relief is the primary goal when treating subjects with chronic pain; however, there are secondary measures that reflect the subjects' overall well-being and functionality. Outcomes related to QoL, as assessed by appropriate measures of functionality, sleep, pain interference, and subject satisfaction, elucidate a more comprehensive picture of the subjects' disposition [10, 15, 24-28]. We present data collected during the SENZA-RCT, demonstrating improved functionality and QoL outcomes for subjects treated with $10 \mathrm{kHz}$ SCS therapy.

\section{Methods}

This study was registered with ClinicalTrials.gov (NCT01609972) on May 30th, 2012 and conducted in compliance with the United States Code of Federal Regulations and in accordance with recommendations of the 18th World Medical Assembly (Helsinki, Finland) guiding physicians in biomedical research. Both the study protocol and informed consent were approved by each participating site's governing institutional review board (Western Institutional Review Board, Puyallup, Washington; Forsyth Medical Center Institutional Review Board, Winston-Salem, North Carolina). All subjects enrolled in the study provided written, informed consent prior to their participation.

A total of 198 subjects with both back and leg pain were randomized 1:1 to either low-frequency, traditional SCS or $10 \mathrm{kHz}$ SCS across ten comprehensive pain treatment centers in the United States. Detailed methods, including subject demographics and subject flow diagram, are described elsewhere [29]. Briefly, a pair of percutaneous leads was placed in the dorsal epidural space along the radiographic midline of the spinal column and stimulation was trialed for up to 14 days. Of the subjects randomized, $189 \mathrm{com}$ pleted the trial phase and 171 of those had a successful trial, defined as $\geq 40 \%$ reduction in back pain as measured by the $10-\mathrm{cm}$ visual analog scale (VAS). The subjects with successful trials were implanted with a permanent SCS system, 90 with $10 \mathrm{kHz}$ SCS (Senza System; Nevro Corp., USA) and 81 with traditional SCS (Precision Plus System; Boston Scientific, USA). Of the 198 subjects (101-10 kHz, 97-low-frequency SCS) randomized to trial stimulation, 
a total of 9 were not trialed $(4-10 \mathrm{kHz}$ SCS and 5-lowfrequency SCS) for the following reasons: $10 \mathrm{kHz}$ SCSmedical contraindication (2), withdrawal of consent (1), lost to follow-up (1); low-frequency SCS-withdrawal of consent (4), medical contraindication (1). Only those with a successful trial ( $\geq 40 \%$ pain relief) proceeded to permanent implant (10 kHz SCS-90 or 92.8\%; low-frequency SCS-81 or $88.0 \%)$.

Under the guidance of the study investigators, SCS devices were programmed by representatives of the respective company according to their best practices. Low-back and leg pain scores (VAS) were collected at all follow-up visits, in addition to measures of functionality [Oswestry Disability Index (ODI) and Global Assessment of Functioning (GAF)], pain interference [Short Form McGill Pain Questionnaire (SF-MPQ-2)], and sleep quality [Pittsburgh Sleep Quality Index (PSQI)]. Overall well-being [Short Form Health Survey (SF-12) and Global Impression of Change (GIC)] data were also captured at baseline and 12-month post-permanent device implant.

ODI assesses the level of disability as "minimal," "moderate," "severe," "crippled," or "bed bound," [30] while GAF categorizes symptoms that affect social, occupational, and school activities as "none," "minimal," "transient," "mild," "moderate," or "serious" [31]. SF-MPQ-2 measures both neuropathic and non-neuropathic (affective) pain associated with a disease condition [32]. GIC assesses the change in severity of a subject's pain over time and involves both a patient's report as well as a clinician's evaluation [33, 34]. PSQI assesses seven subscales related to sleep that together add up to a global score [35].

ODI has been validated in a low-back pain population $[30,36]$, whereas SF-MPQ-2 was validated for use in clinical research with neuropathic and non-neuropathic pain conditions [32]. SF-12 is an established, generic measure of health status used in various disease conditions [37]. All of the above listed questionnaires along with GIC were recommended health-related quality of life (HRQOL) outcomes in chronic pain trials by the Initiative on Methods, Measurement and Pain Assessment in Clinical Trials (IMMPACT) [38]. Current traditional SCS therapies can cause sudden changes in paresthesias with activities as the position of the stimulating electrode and spinal cord varies [39]. Frequent interaction with the device, by changing the stimulation or turning the therapy off to avoid unwanted shocks, may be perceived as burdensome to patient's normal daily routine. To explore this question, subjects returning for their 24-month follow-up visit were asked how often they used their remote programmers and whether they carried it with them when they left the house. Also, the continuous usage of stimulation including while sleeping and during activities without having to frequently change stimulation settings could be surrogate marker for good pain relief and quality of life.

Data are presented as the median and $95 \%$ confidence interval (CI) of the median. In outcomes where no baseline values are available for comparison, data are presented as median and their interquartile range (IQR). Categorical variables were compared using either Fisher's exact test or Mann-Whitney test if there was evidence of non-normality in the data. This study was powered for the primary endpoint of responder rate with a hierarchical testing procedure performed for secondary endpoints (all of which were determined to be significant) [29]. The quality of life outcomes reported in the current manuscript were tertiary or observational outcomes, and therefore were not subject to hierarchical testing. As such, we report nominal $p$ values without correction.

\section{Results}

\section{Oswestry Low-Back Pain Disability Questionnaire (ODI)}

There was no difference between the two groups in baseline ODI scores, whether analyzing average raw scores (difference in medians: 2.00 [95\% CI 0.00-5.33], $p=.141$, exact non-parametric Mann-Whitney test, 2-sided) or distribution of subjects among the subcategories $(p=.228$, exact non-parametric Mann-Whitney test, 2-sided). At 12 months, however, there was a notable improvement for the $10 \mathrm{kHz}$ SCS group compared with traditional SCS subjects in both average raw scores (difference in medians: 6.00 [95\% CI 1.56-11.12], $p=.016$, exact non-parametric Mann-Whitney test, 2-sided) and distribution of subjects among the subcategories $(p=.010$, exact non-parametric Mann-Whitney test, 2-sided) (Fig. 1). Within the $10 \mathrm{kHz}$ SCS group, $69.6 \%$ of subjects had an improved ODI score sufficient to reclassify them into a lower disability category, whereas $55.1 \%$ of traditional SCS subjects were in a lower disability grouping at 12 months (Table 1). The specific distribution of subjects among subcategories has been previously reported [29].

\section{Global Assessment of Functioning (GAF)}

Baseline scores were 65.00 (IQR 15.00) and 65.00 (IQR $18.25)$ for $10 \mathrm{kHz}$ SCS and traditional SCS groups, respectively (difference in median: 0.00 [95\% CI $-2.00-5.00]$, $p=.511$ ). Improvement in GAF scores at 12 months compared to baseline was 14.00 (IQR 15.00) in the $10 \mathrm{kHz}$ SCS group and 6.50 (IQR 19.00) in the traditional SCS group. Therefore, improvement in GAF scores for $10 \mathrm{kHz}$ SCS 
Fig. 1 Distribution of subjects amongst the subcategories of Oswestry Disability Index (ODI) in the traditional SCS and $10 \mathrm{kHz}$ SCS groups at baseline and at 12 months

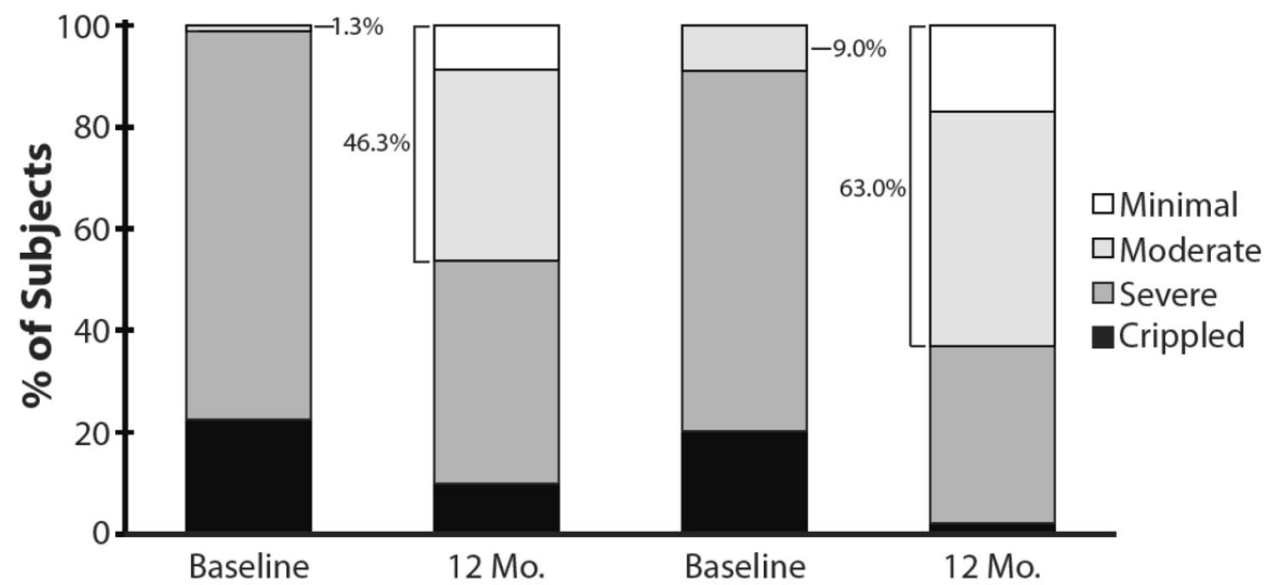

Traditional SCS

$10 \mathrm{kHz}$ SCS

Table 1 The number and percentage of subjects stratified into "minimal," "moderate," "severe," "crippled", or "bedbound" categories by the ODI administered at baseline and 12 months

\begin{tabular}{|c|c|c|c|c|c|}
\hline \multirow{2}{*}{$\begin{array}{l}\text { A. Traditional SCS } \\
N=80\end{array}$} & & \multicolumn{4}{|l|}{12 months } \\
\hline & & Minimal & Moderate & Severe & Crippled \\
\hline \multirow[t]{5}{*}{ Baseline } & Minimal & - & - & - & - \\
\hline & Moderate & $1(1.3 \%)$ & 0 & $\mathbf{0}$ & $\mathbf{0}$ \\
\hline & Severe & $6(7.5 \%)$ & $25(31.3 \%)$ & $28(35.0 \%)$ & $2(2.5 \%)$ \\
\hline & Crippled & 0 & $5(6.3 \%)$ & $7(8.8 \%)$ & $6(7.5 \%)$ \\
\hline & Bedbound & - & - & - & - \\
\hline \multirow{2}{*}{$\begin{array}{l}\text { B. } 10 \mathrm{kHz} \text { SCS } \\
N=89\end{array}$} & & \multicolumn{4}{|l|}{12 months } \\
\hline & & Minimal & Moderate & Severe & Crippled \\
\hline \multirow[t]{5}{*}{ Baseline } & Minimal & - & - & - & - \\
\hline & Moderate & $4(4.5 \%)$ & $4(4.5 \%)$ & $\mathbf{0}$ & $\mathbf{0}$ \\
\hline & Severe & $9(10.1 \%)$ & $32(36.0 \%)$ & $21(23.6 \%)$ & $1(1.1 \%)$ \\
\hline & Crippled & $2(2.2 \%)$ & $5(5.6 \%)$ & $10(11.2 \%)$ & $1(1.1 \%)$ \\
\hline & Bedbound & - & - & - & - \\
\hline
\end{tabular}

The number of subjects who improved from baseline are in normal font, the number with no change from baseline are in Italics, and the number who worsened are in bold. For traditional SCS subjects (A), 44 (55.1\%) improved by at least one category. For $10 \mathrm{kHz}$ SCS subjects (B), 62 (69.6\%) improved by one or more categories

group was higher than that reported in the traditional SCS group (difference in medians: 5.00, [95\% CI 0.10-10.00], $p<.01$, Mann-Whitney test). The specific distribution of subjects among subcategories has been previously reported [29].

\section{Short Form McGill Pain Questionnaire 2 (SF-MPQ-2)}

Compared to their respective baseline values, both traditional SCS and $10 \mathrm{kHz}$ SCS subjects reported reductions in all components of pain and affective disorder subscales on the SF-MPQ-2. Comparisons between the two treatment groups at 12 months revealed that $10 \mathrm{kHz}$ SCS subjects reported greater improvements than their traditional SCS counterparts in continuous (difference in medians: 1.17 , [95\% CI 2.00-0.50], $p<.005$ ), intermittent (difference in medians: 1.33 , [95\% CI 2.00-0.50], $p<.005$ ), and neuropathic pain (difference in medians: 0.83 , [95\% CI $1.50-0.17], p<.01$, Mann-Whitney non-parametric test). However, there was no difference between the treatment groups on the affective disorders subscale (Fig. 2, difference in medians: 0.25 , [95\% CI $0.00-0.75], p=.080$, Mann-Whitney non-parametric test). 

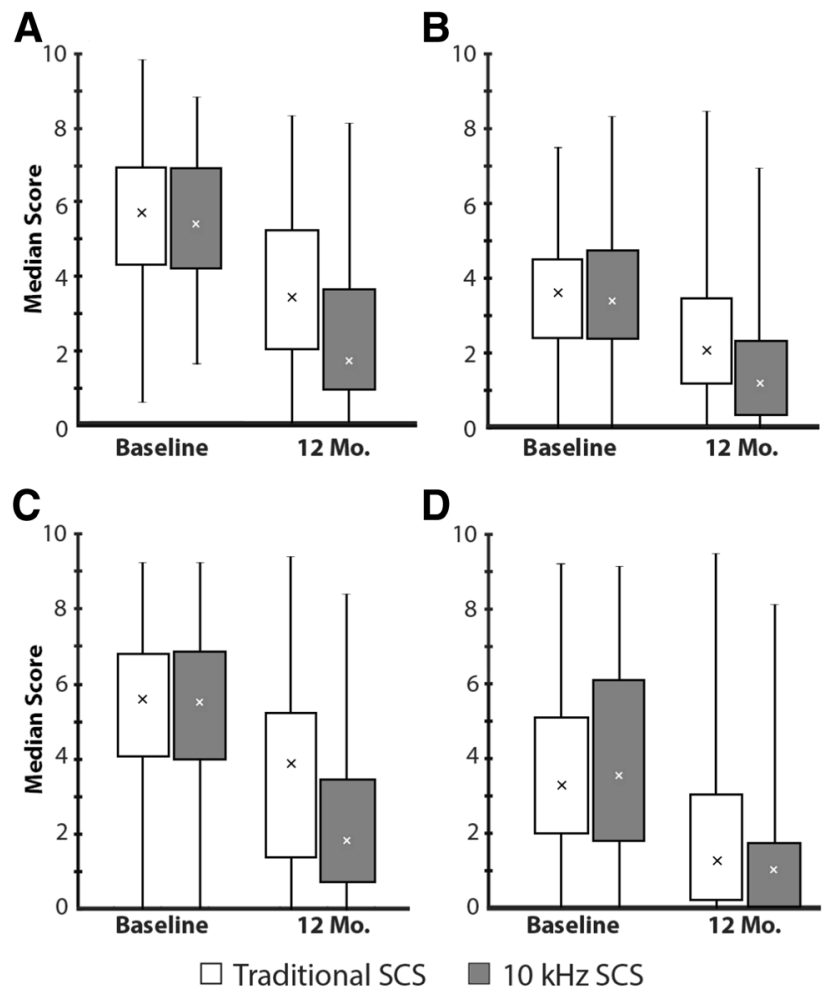

Fig. 2 Average scores at baseline and 12 months assessed by the SFMPQ-2. Data are presented as median and interquartile range with upper and lower bounds for the subscales of continuous pain (A), neuropathic pain $(\mathbf{B})$, intermittent pain $(\mathbf{C})$, and affective descriptors (D)

\section{Item Short Form Survey (SF-12)}

The results of the SF-12 questionnaire are reported as two separate subscale scores: a physical health composite score (PCS) and a mental health composite score (MCS). Both the traditional and $10 \mathrm{kHz}$ SCS groups showed improvement from baseline in their PCS and MCS (Fig. 3). In PCS, the differences in medians for $10 \mathrm{kHz}$ SCS and traditional SCS were 7.97 [95\% CI 5.72-10.39] and 6.20 [95\% CI 3.70-8.78], respectively. In MCS, the differences in medians for $10 \mathrm{kHz}$ SCS and traditional SCS were 3.77 [95\% CI 0.13-7.53] and 2.10 [95\% CI 1.26-5.55], respectively. There was no statistical difference between the groups in either score.

\section{Global Impression of Change (GIC)}

On the Patient Global Impression of Change (PGIC) questionnaire collected at 12 months, $42.0 \%$ of traditional SCS subjects reported feeling "better" or "a great deal better," compared to $57.3 \%$ of $10 \mathrm{kHz}$ SCS subjects (Fig. 4A, $p=.052$, Fisher's exact test, 2-sided). On the Clinician Global Impression of Change (CGIC) questionnaire collected at 12 months, 56.5\% of traditional SCS subjects were rated by their physician as "better" or "a great deal better," compared to $75.0 \%$ of $10 \mathrm{kHz}$ SCS subjects (Fig. 4B, $p=.009$, Fisher's exact test, 2-sided).

\section{Sleeping or driving with stimulation on}

At 12 months, 82 of 86 , or $95.3 \%$, of the $10 \mathrm{kHz}$ SCS subjects reported leaving the stimulator on while sleeping, whereas 41 of 69 , or $59.4 \%$, of the traditional SCS subjects did the same (Table 2, $p<.001$, Fisher's exact test, 2-sided). Seventy six of 81 , or $93.8 \%$, of the $10 \mathrm{kHz}$ SCS subjects also reported that they drive with the stimulator turned on, compared to 40 of 61 , or $65.6 \%$, of traditional SCS subjects who reported doing the same (Table $2, p<.001$, Fisher's exact test, 2-sided).

\section{Pittsburgh Sleep Quality Assessment (PSQI)}

The PSQI collects data from seven 4-point subscales that collectively make up the global score. On 6 of the 7 subscales, a higher proportion of $10 \mathrm{kHz}$ SCS subjects improved compared with traditional SCS subjects. The improvement with $10 \mathrm{kHz}$ SCS subjects was noted to be in subjective sleep quality, improved sleep latency and duration, better habitual sleep efficiency, reduced use of sleep medications, and less daytime dysfunction. A PSQI global score of 5 or greater indicates poor sleep quality. There was no difference between the two groups in proportion of "good sleepers" to "poor sleepers" at baseline ( $p=.587$, Fisher's exact test, 2 -sided). At 12 months, there was no increase in the number of traditional SCS subjects with good sleep quality but there was an observable increase in the number of "good sleepers" among the $10 \mathrm{kHz}$ SCS group compared to traditional SCS subjects ( $p=.001$, Fisher's exact test, 2-sided).

\section{Reliance on Patient Remote Programmer}

At 24 months, subjects were asked to complete an optional survey about their use and reliance on their programmer, including if they took it outside of their homes and if they used it daily ( $n=55$ for $10 \mathrm{kHz}$ SCS and $n=40$ for traditional SCS). Approximately $85 \%$ of the subjects treated with traditional SCS, reported carrying their programmer outside of their homes and $35.4 \%$ used their programmers daily. Only $38.2 \%$ of $10 \mathrm{kHz}$ SCS subjects carried the device with them when they left the house. None of the $10 \mathrm{kHz}$ SCS subjects used their remote programming device daily.

\section{Discussion}

When evaluating treatments for chronic, intractable pain, the paramount focus should be on the magnitude of reduction in pain scores. However, improvement in quality of life 
Fig. 3 Subject well-being as captured at baseline and the 12-month follow-up with the SF-12 questionnaire and reported as two separate subscale scores: a physical health composite score (PCS) and a mental health composite score (MCS)
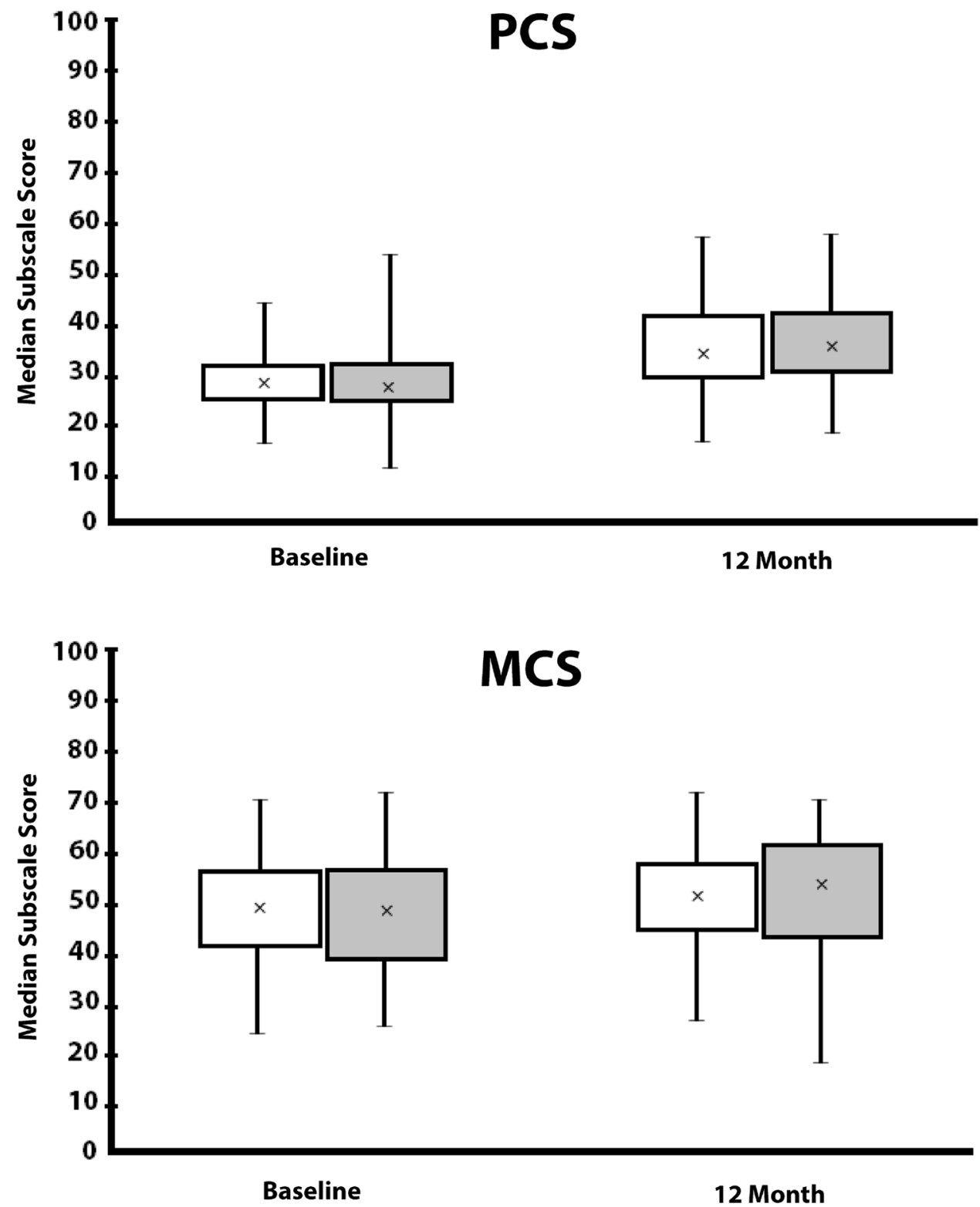

metrics may not be neglected, as they add a comprehensive overview at patient's overall function and well-being. The SENZA-RCT not only demonstrated superior pain relief for $10 \mathrm{kHz}$ SCS subjects with chronic low-back and leg pain compared to subjects treated with traditional SCS [29], but it also demonstrated greater improvements across a variety of QoL measures, including the ODI, GAF, SF-MPQ-2, GIC, PSQI, and subject remote programmer usage.

One assay, the SF-12, showed improvements from baseline, but did not statistically differ between the two treatment groups. This instrument is designed to measure QoL and functionality in a wide variety of patient populations and may lack the sensitivity to detect a difference between the SENZA-RCT treatment groups [40]. In addition, the SENZA-RCT was powered for the primary endpoint of responder rates and not the secondary, QoL endpoints. Thus, a larger sample size may be necessary to detect differences on the SF-12 questionnaire. Similarly, this study was not powered to detect differences in sleep quality as measured by the PSQI, although we do see a notable increase in the number of $10 \mathrm{kHz}$ SCS subjects at 12 months who score in the "good sleeper" category on the global scale, while there was no change for traditional SCS subjects. A larger sample size may help elucidate which 
A

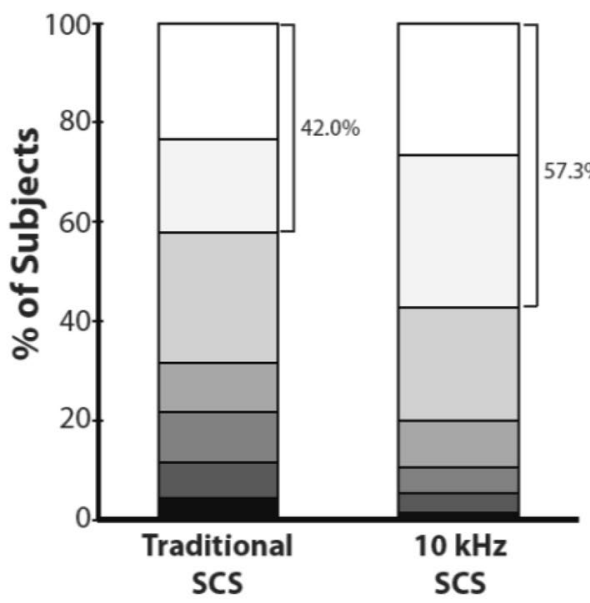

B

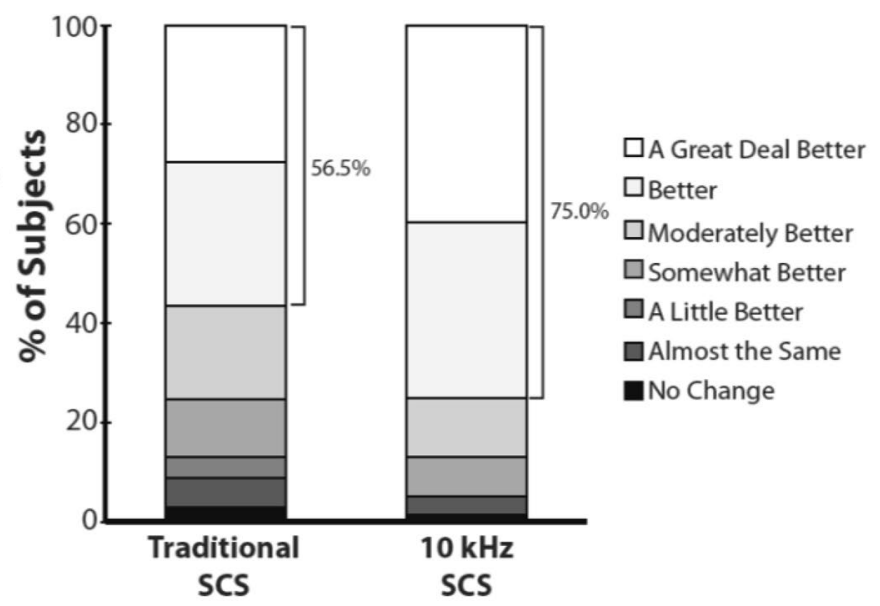

Fig. 4 The percentage of subjects categorized into "a great deal better," "better," "moderately better," "somewhat better," "a little better," "almost the same," or "no change" by the GIC administered at 12 months. This assessment is completed by both the patient (PGIC,

Table 2 Subject device usage while sleeping or driving

\begin{tabular}{lll}
\hline & \multicolumn{1}{c}{ Traditional SCS } & $10 \mathrm{kHz}$ SCS \\
& $N=69$ & $N=86$ \\
\hline \multicolumn{2}{l}{ Sleep with stimulation turned on? } \\
Yes & $41(59.4 \%)$ & $82(95.3 \%)$ \\
No & $28(40.6 \%)$ & $4(4.7 \%)$ \\
Drive with stimulation turned on? & \\
Yes & $40(65.6 \%)$ & $76(93.8 \%)$ \\
No & $21(34.4 \%)$ & $5(6.2 \%)$ \\
NA & 8 & 5 \\
\hline
\end{tabular}

Results of subject questionnaire at 12 months about SCS use during sleep and while driving. Data are reported as $N(\%)$. NA indicates subjects that do not drive; thus, the percentages are based on only subjects who drive

specific aspects of sleep quality improve for $10 \mathrm{kHz}$ SCS subjects. It is noteworthy that this scale has been shown to correlate strongly with measures of depression, anxiety, stress, and a negative outlook [41, 42].

Traditional SCS subjects reported much higher daily usage of their programmers and were more likely to carry it with them than subjects being treated with $10 \mathrm{kHz}$ SCS. This suggests that those being treated with $10 \mathrm{kHz}$ were less burdened by the needs of the therapy. It is possible that the uncomfortable paresthesia reported in the traditional SCS group could have attributed to this behavior. Majority (95.5\%) of subjects receiving traditional SCS experienced paresthesia and of those, $11.1 \%$ found it uncomfortable and $39.7 \%$ experienced discomfort with changes in posture. The uncomfortable paresthesia elicited by traditional SCS could
A) and the clinician (CGIC, B). The total percentage of subjects whose change from baseline was classified as either "a great deal better" or "better" is indicated next to each bar

also explain the difference in device usage $(10 \mathrm{kHz}$ SCS: $24 \pm 0.1 \mathrm{~h} /$ day versus traditional SCS: $17.0 \pm 7.3 \mathrm{~h} /$ day).

Another concept which may help interpret clinical outcomes and simplify treatment algorithms would be to establish what constitutes a minimal clinically important difference (MCID) for a variety of measures commonly used in chronic pain research. MCID is defined as "The smallest difference in score in the domain of interest which patients perceive as beneficial and which would mandate, in the absence of troublesome side effects and excessive cost, a change in the patient's management" [43]. Few studies assessing SCS therapy have examined MCID in functional and QoL outcomes. Defining MCID threshold for QoL assessments would help identify what level of score improvement an intervention is of noticeable benefit to the patient; therefore, potentially worth the attendant risks. For the ODI, several studies have defined a range of absolute value changes in the overall score as an MCID [44-48]. An analysis of the SENZA-RCT ODI data per the MCID definitions established in these studies demonstrate the responder rates for both traditional SCS and $10 \mathrm{kHz}$ SCS subjects at 12 months which is depicted in Fig. 5. Regardless of how conservative the definition of the MCID is, approximately $10-15 \%$ more $10 \mathrm{kHz}$ SCS subjects achieved an MCID than their traditional SCS counterparts. Presenting the data in this manner, as the proportion of subjects who report a MCID from their baseline score, will provide a standard by which a physician can evaluate the clinical significance of an improved score. Further research to establish MCID thresholds for additional QoL assessments would be of tremendous value. 


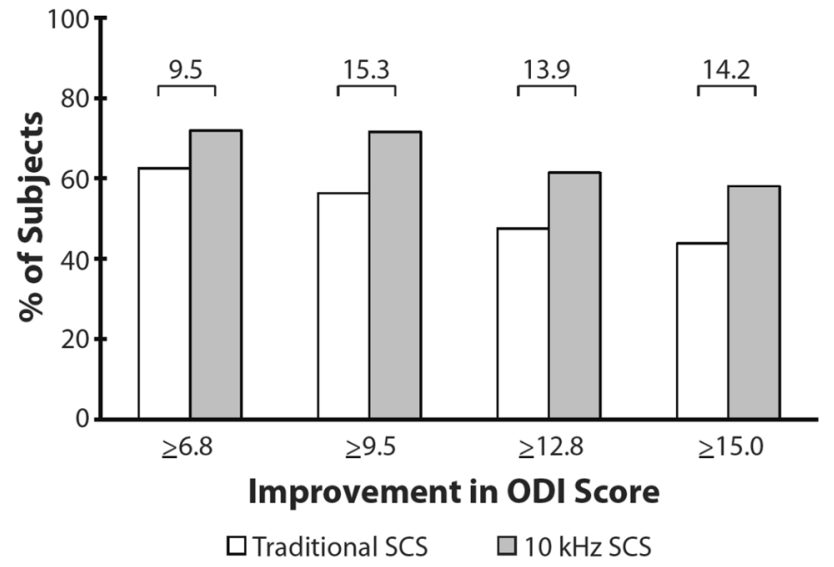

Fig. 5 The percentage of subjects achieving an improvement in ODI score that meets or exceeds the definition of a MCID, as previously defined in the literature. The difference between comparable bars is shown above each pair

Prior publications have demonstrated the safety, efficacy, and stability of $10 \mathrm{kHz}$ SCS for long-term treatment of chronic, intractable pain of the trunk and limbs, including the axial low-back [23, 29, 49]. Results presented here further demonstrate that $10 \mathrm{kHz}$ SCS markedly improves secondary outcomes that reflect the subjects' better health, functionality, and overall well-being. The higher subject satisfaction scores could be due to the absence of paresthesias with $10 \mathrm{kHz}$ SCS and/or the superior, stable pain relief. Based on the available data, it is reasonable to postulate that a high degree of pain relief, in the absence of paresthesias, enables the subjects to carry out daily activities, including driving and sleeping, without experiencing unwanted stimulation from postural changes, a common complaint with traditional low-frequency SCS systems [50, 51].

A limitation of the study was that these tertiary endpoints were not powered to assess multiple hypothesis tests. Other study limitations include the subjects and the investigators not being masked to the assigned treatment group and the heterogeneity of pain diagnoses, as previously discussed [23].

The SENZA-RCT not only demonstrated sustainably improved pain scores with $10 \mathrm{kHz}$ SCS, but it also improved measures related to quality of life in a clinically meaningful manner, superior to traditional SCS for this given pain patient population.

Acknowledgements The authors would like to thank all the SENZA investigators for their invaluable contributions to this study. We would also like to thank Mona Maneshi and Drew Brawner for assistance preparing this manuscript.

Funding Funding for this study was provided by Nevro Corp., Redwood City, CA.

\section{Compliance with ethical standards}

Conflict of interest KA: Personal fees from Nevro Corp., Saluda Medical, and Abbott. Grants from Nevro Corp., Mesoblast, Abbott, Saluda and Biotronik. Scientific advisory board member of Mesoblast, Nalu Medical and Biotronik. CY: Personal fees from Boston Scientific, Medtronic, and St. Jude Medical. LK: Grants from Nevro Corp., Boston Scientific, and Saluda Medical and personal fees from Medtronic, Stimwave and St. Jude Medical. BEG, ESB, AAP and JS: Employees of Nevro Corp. RV: Grants from Nevro Corp. and Boston Scientific and personal fees from Boston Scientific. RB (Coastal Orthopedics and Pain Medicine): Personal fees (speaking engagements) and research grants from Nevro Corp. TLY: Research grants from Boston Scientific, Nevro Corp., and St. Jude Medical; Consulting agreements with Boston Scientific, Nevro Corp., St. Jude Medical and Neuronano; Officer in Meagan Medical (Chief Medical Officer) and Algos Clinical Development (Director). RB (Millennium Pain Center): Consulting agreement with Medtronic; Research Grants from Medtronic, Boston Scientific, St. Jude Medical and Nevro Corp. TY: Consulting agreement with Nevro Corp. MWD, DMM, BTS, AHB: No conflict.

Ethical approval This study was registered with ClinicalTrials.gov (NCT01609972) on May 30th, 2012 and conducted in compliance with the United States Code of Federal Regulations and in accordance with recommendations of the 18th World Medical Assembly (Helsinki, Finland) guiding physicians in biomedical research. Both the study protocol and informed consent were approved by each participating site's governing institutional review board (Western Institutional Review Board, Puyallup, Washington; Forsyth Medical Center Institutional Review Board, Winston-Salem, North Carolina).

Informed consent All subjects enrolled in the study provided written, informed consent prior to their participation.

Open Access This article is distributed under the terms of the Creative Commons Attribution 4.0 International License (http://creativeco mmons.org/licenses/by/4.0/), which permits unrestricted use, distribution, and reproduction in any medium, provided you give appropriate credit to the original author(s) and the source, provide a link to the Creative Commons license, and indicate if changes were made.

\section{References}

1. Vos, T., Flaxman, A. D., Naghavi, M., Lozano, R., Michaud, C., Ezzati, M., et al. (2012). Years lived with disability (YLDs) for 1160 sequelae of 289 diseases and injuries 1990-2010: a systematic analysis for the Global Burden of Disease Study 2010. Lancet, 380(9859), 2163-2196.

2. Hoy, D., March, L., Brooks, P., Blyth, F., Woolf, A., Bain, C., et al. (2014). The global burden of low back pain: Estimates from the Global Burden of Disease 2010 Study. Annals of the Rheumatic Diseases, 73(6), 968-974.

3. Shmagel, A., Foley, R., \& Ibrahim, H. (2016) Epidemiology of chronic low back pain in US adults: National Health and Nutrition Examination Survey 2009-2010. Arthritis Care Res (Hoboken). https://doi.org/10.1002/acr.22890.

4. Burton, A. K., Balagué, F., Cardon, G., Eriksen, H. R., Henrotin, Y., Lahad, A., et al. (2006). Chapter 2 European guidelines for prevention in low back pain: November 2004. European Spine Journal, 15(Suppl 2), S136-S168. 
5. Luo, X., Pietrobon, R., Sun, S. X., Liu, G. G., \& Hey, L. (2004). Estimates and patterns of direct health care expenditures among individuals with back pain in the United States. Spine (Phila Pa 1976), 29(1), 79-86.

6. Dagenais, S., Caro, J., \& Haldeman, S. (2008). A systematic review of low back pain cost of illness studies in the United States and internationally. The Spine Journal, 8(1), 8-20.

7. Manchikanti, L., Singh, V., Falco, F. J., Benyamin, R. M., \& Hirsch, J. A. (2014). Epidemiology of low back pain in adults. Neuromodulation, 17(Suppl 2), 3-10.

8. Institute of Medicine Committee on Advancing Pain Research, C., and Education. (2011). Care of people with pain, relieving pain in America: A blueprint for transforming prevention, care, education, and research. Washington, DC: National Academies Press.

9. Oakley, J. C., \& Weiner, R. L. (1999). Spinal cord stimulation for complex regional pain syndrome: A prospective study of 19 patients at two centers. Neuromodulation, 2(1), 47-50.

10. Kumar, K., Taylor, R. S., Jacques, L., Eldabe, S., Meglio, M., Molet, J., et al. (2007). Spinal cord stimulation versus conventional medical management for neuropathic pain: A multicentre randomised controlled trial in patients with failed back surgery syndrome. Pain, 132(1-2), 179-188.

11. Kumar, K., Hunter, G., \& Demeria, D. (2006). Spinal cord stimulation in treatment of chronic benign pain: Challenges in treatment planning and present status, a 22-year experience. Neurosurgery, 58(3), 481-496 (discussion 481-496).

12. De Vries, J., De Jongste, M. J. L., Spincemaille, G., \& Staal, M. J. (2007). Spinal cord stimulation for ischemic heart disease and peripheral vascular disease. Advances and Technical Standards in Neurosurgery, 32, 63-89.

13. Barolat, G., Massaro, F., He, J., Zeme, S., \& Ketcik, B. (1993). Mapping of sensory responses to epidural stimulation of the intraspinal neural structures in man. Journal of Neurosurgery, $78(2), 233-239$

14. Melzack, R., \& Wall, P. D. (1965). Pain mechanisms: A new theory. Science, 19(150), 971-979.

15. Kumar, K., Taylor, R. S., Jacques, L., Eldabe, S., Meglio, M., Molet, J., et al. (2008) The effects of spinal cord stimulation in neuropathic pain are sustained: A 24-month follow-up of the prospective randomized controlled multicenter trial of the effectiveness of spinal cord stimulation. Neurosurgery, 63(4), 762-770 (discussion 770).

16. Kemler, M. A., De Vet, H. C., Barendse, G. A., Van Den Wildenberg, F. A., \& Van Kleef, M. (2004). The effect of spinal cord stimulation in patients with chronic reflex sympathetic dystrophy: Two years' follow-up of the randomized controlled trial. Annals of Neurology, 55(1), 13-18.

17. Kumar, K., Nath, R., \& Wyant, G. M. (1991). Treatment of chronic pain by epidural spinal cord stimulation: A 10-year experience. Journal of Neurosurgery, 75(3), 402-407.

18. North, R. B., Kidd, D. H., Zahurak, M., James, C. S., \& Long, D. M. (1993) Spinal cord stimulation for chronic, intractable pain: Experience over two decades. Neurosurgery, 32(3), 384-394 (discussion 394-395).

19. Oakley, J. (2006). Spinal cord stimulation in axial low back pain: Solving the dilemma. Pain Medicine, 7(S1), 58-63.

20. Cameron, T., \& Alo, K. M. (1998) Effects of posture on stimulation parameters in spinal cord stimulation. Neuromodulation: Technology at the Neural Interface, 1(4), 177-183.

21. Ross, E., \& Abejón, D. (2014) Improving patient experience with spinal cord stimulation: Implications of position-related changes in neurostimulation. Neuromodulation: Technology at the Neural Interface, 17, 36-41.

22. De Carolis, G., et al. (2017). Paresthesia-independence: An assessment of technical factors related to $10 \mathrm{kHz}$ paresthesia-free spinal cord stimulation. Pain Physician, 20(4), 331-341.
23. Kapural, L., Yu, C., Doust, M. W., Gliner, B. E., Vallejo, R., Sitzman, B. T., et al. (2016). Comparison of 10-kHz high-frequency and traditional low-frequency spinal cord stimulation for the treatment of chronic back and leg pain: 24-month results from a multicenter, randomized, controlled pivotal trial. Neurosurgery, 79(5), 667-677.

24. Pluijms, W. A., Slangen, R., Bakkers, M., Faber, C. G., Merkies, I. S. J., Kessels, A. G., et al. (2012). Pain relief and quality-oflife improvement after spinal cord stimulation in painful diabetic polyneuropathy: A pilot study. British Journal of Anaesthesia, 109(4), 623-629.

25. Andrell, P., Yu, W., Gersbach, P., Gillberg, L., Pehrsson, K., Hardy, I., et al. (2010). Long-term effects of spinal cord stimulation on angina symptoms and quality of life in patients with refractory angina pectoris-results from the European Angina Registry Link Study (EARL). Heart, 96(14), 1132-1136.

26. Lanza, G. A., Grimaldi, R., Greco, S., Ghio, S., Sarullo, F., Zuin, G., et al. (2011). Spinal cord stimulation for the treatment of refractory angina pectoris: A multicenter randomized single-blind study (the SCS-ITA trial). Pain, 152(1), 45-52.

27. Manca, A., Kumar, K., Taylor, R. S., Jacques, L., Eldabe, S., Meglio, M., et al. (2008). Quality of life, resource consumption and costs of spinal cord stimulation versus conventional medical management in neuropathic pain patients with failed back surgery syndrome (PROCESS trial). European Journal of Pain, 12(8), $1047-1058$.

28. Spincemaille, G. H., Klomp, H. M., Steyerberg, E. W., \& Habbema, J. D. F. (2000). Pain and quality of life in patients with critical limb ischaemia: Results of a randomized controlled multicentre study on the effect of spinal cord stimulation. ESES study group. European Journal of Pain, 4(2), 173-184.

29. Kapural, L., Yu, C., Doust, M. W., Gliner, B. E., Vallejo, R., Sitzman, B. T., et al. (2015). Novel 10-kHz high-frequency therapy (HF10 therapy) is superior to traditional low-frequency spinal cord stimulation for the treatment of chronic back and leg pain. The SENZA-RCT randomized controlled trial. Anesthesiology, 123(4), 851-860.

30. Fairbank, J. C., Couper, J., \& O’Brien, J. P. (1980). The Oswestry low back pain disability questionnaire. Physiotherapy, 66(8), 271-273.

31. Hall, R. C. (1995). Global assessment of functioning. A modified scale. Psychosomatics, 36(3), 267-275.

32. Dworkin, R. H., Turk, D. C., Revicki, D. A., Harding, G., Coyne, K. S., Peirce-Sandner, S., et al. (2009). Development and initial validation of an expanded and revised version of the Short-form McGill Pain Questionnaire (SF-MPQ-2). Pain, 144(1-2), 35-42.

33. Fischer, D., Stewart, A. L., Bloch, D. A., Lorig, K., Laurent, D., \& Holman, H. (1999). Capturing the patient's view of change as a clinical outcome measure. JAMA, 282(12), 1157-1162.

34. ECDEU assessment manual for psychopharmacology. (1976). Rockville: U.S. Department of Health, Education, and Welfare.

35. Buysse, D. J., Reynolds, C. F., Monk, T. H., Berman, S. R., \& Kupfer, D. J. (1989). The Pittsburgh Sleep Quality Index: A new instrument for psychiatric practice and research. Psychiatry Research, 28(2), 193-213.

36. Fairbank, J. C. T., \& Pynsent, P. B. (2000). The Oswestry Disability Index. Spine, 25(22), 2940-2953.

37. Jenkinson, C., Layte, R., Jenkinson, D., Lawrence, K., Petersen, S., Paice, C., \& Stradling, J. (1997). A shorter form health survey: Can the SF-12 replicate results from the SF-36 in longitudinal studies? Journal of Public Health Medicine, 19(2), 179-186.

38. Dworkin, R. H., Turk, D. C., Farrar, J. T., Haythornthwaite, J. A., Jensen, M. P., Katz, N. P., et al. (2005). Core outcome measures for chronic pain clinical trials: IMMPACT recommendations. PAIN, 113(1), 9-19. 
39. Barolat, G., Oakley, J. C., Law, J. D., North, R. B., Ketcik, B., \& Sharan, A. (2001). Epidural spinal cord stimulation with a multiple electrode paddle lead is effective in treating intractable low back pain. Neuromodulation, 4(2), 59-66.

40. Ware, J. Jr., Kosinski, M., \& Keller, S. D. (1996). A 12-Item ShortForm Health Survey: Construction of scales and preliminary tests of reliability and validity. Medical Care, 34(3), 220-233.

41. Dietch, J. R., Taylor, D. J., Sethi, K., Kelly, K., Bramoweth, A. D., \& Roane, B. M. (2016). Psychometric evaluation of the PSQI in U.S. college students. Journal of Clinical Sleep Medicine, 12(8), 1121-1129.

42. Grandner, M. A., Kripke, D. F., Yoon, I. Y., \& Youngstedt, S. D. (2006). Criterion validity of the Pittsburgh Sleep Quality Index: Investigation in a non-clinical sample. Sleep and Biological Rhythms, 4(2), 129-139.

43. Jaeschke, R., Singer, J., \& Guyatt, G. H. (1989). Measurement of health status. Ascertaining the minimal clinically important difference. Controlled Clinical Trials, 10(4), 407-415.

44. Parker, S. L., Mendenhall, S. K., Shau, D., Adogwa, O., Cheng, J. S., Anderson, W. N., et al. (2012). Determination of minimum clinically important difference in pain, disability, and quality of life after extension of fusion for adjacent-segment disease. Journal of Neurosurgery Spine, 16(1), 61-67.

45. Monticone, M., Baiardi, P., Vanti, C., Ferrari, S., Pillastrini, P., Mugnai, R., \& Foti, C. (2012). Responsiveness of the Oswestry Disability Index and the Roland Morris Disability Questionnaire in Italian subjects with sub-acute and chronic low back pain. European Spine Journal, 21(1), 122-129.
46. Copay, A. G., Glassman, S. D., Subach, B. R., Berven, S., Schuler, T. C., \& Carreon, L. Y. (2008). Minimum clinically important difference in lumbar spine surgery patients: A choice of methods using the Oswestry Disability Index, Medical Outcomes Study Questionnaire Short Form 36, and pain scales. The Spine Journal, 8(6), 968-974.

47. Glassman, S. D., Berven, S., Kostuik, J., Dimar, J. R., Horton, W. C., \& Bridwell, K. (2006). Nonsurgical resource utilization in adult spinal deformity. Spine (Phila Pa 1976), 31(8), 941-947.

48. Johnsen, L. G., Hellum, C., Nygaard, ØP., Storheim, K., Brox, J. I., Rossvoll, I., et al. (2013). Comparison of the SF6D, the EQ5D, and the oswestry disability index in patients with chronic low back pain and degenerative disc disease. BMC Musculoskeletal Disorders, 14, 148.

49. Al-Kaisy, A., Buyten, V., Smet, I., Palmisani, S., Pang, D., \& Smith, T. (2014). Sustained effectiveness of $10 \mathrm{kHz}$ high-frequency spinal cord stimulation for patients with chronic, low back pain: 24-month results of a prospective multicenter study. Pain Medicine, 15(3), 347-354.

50. Olin, J. C., Kidd, D. H., \& North, R. B. (1998). Postural changes in spinal cord stimulation perceptual thresholds. Neuromodulation, 1(4), 171-175.

51. Schultz, D. M., Webster, L., Kosek, P., Dar, U., Tan, Y., \& Sun, M. (2012). Sensor-driven position-adaptive spinal cord stimulation for chronic pain. Pain Physician, 15(1), 1-12. 